\title{
Problems of Statistics in the Greek Linguistic Studies: A Computational Approach
}

\author{
Abdelmonem Ahmed Zaki ${ }^{* 1}$ \\ Faculty of Arts, Ain Shams University \\ abdelmoneam. ahmedeart. asu.edu.eg
}

\begin{abstract}
This paper aims to explain why we would use statistical methods for Ancient Greek linguistics? The statistics are typically using a large machine-readable corpus, in order to discover general principles of linguistic behavior, genre difference, etc. The paper also sets out to prove some hypotheses, or identify some linguistic phenomena, such as morphological, syntactic, and semantic phenomena.
\end{abstract}

The proposed paper will consist of the following points:

- What kinds of linguistic data can they handle?

- What are the advantages and disadvantages of statistical linguistics?

- What is the nature of the assumptions they require of the analyst?

- What is the strategy for studying of linguistic phenomena?

Keywords: Statistical Linguistics, Linguistic Phenomenon, Greek Linguistics, Computational Approach. Morphological Classification, Semantic Classification.

\section{INTRODUCTION}

In 1959, N. Chomsky said that statistical approaches will always suffer from lack of data, and that language should be analyzed at a deeper level [1]. In 2007, he said also that it was commonly assumed that statistical analysis of vast corpora should reveal everything there is to learn about language and its acquisition [2].

So Chomsky believes that the statistical analysis is not enough to study the language, and here begins the issue, statistics suitable for studying all linguistic phenomena? Is it possible to rely on statistical results in the formation of linguistic base? And why do linguists need statistical analysis?

A. Problem of the Study:

Many linguistic studies are based on statistical analysis, but, do the statistics fit for the study of all linguistic levels such as: phonology, morphological, syntactic, and semantic? And, is it possible to rely on statistical results in the formation of linguistic base?

B. Aims of the study:

- To present a methodology for statistical analysis of ancient Greek texts.

- Propose a computational system that includes a data base of Greek vocabulary, to help researchers in understanding the different Greek linguistic phenomena through statistics.

C. Axes of the study:

The researcher divides the study into two levels:

- Level I: Statistical analysis of the Greek language problems.

- Level II: foundations that must be followed to create a computer system capable of statistical analysis of the Greek language.

D. Resources of the study:

The researcher relied on the Thesaurus Graecae Linguae (TLG), which is a comprehensive library of the most ancient Greek texts.

E. Computational tools:

- Search programs in classical texts, like, Musaios, and Diogenes.

- The researcher used the Perseus site to study the classical texts:[3]

- The researcher also used the analyzes $\mathrm{N}$-gram [ [] through the site: Ht tp://guidetodatamining.com/ngramAnalyzer

\section{WHAT IS STATISTICAL LINGUISTICS?}

Statistics is the science of learning from data, and of measuring, controlling, and communicating uncertainty; and it thereby provides the navigation essential for controlling the course of scientific and societal advances [4]. Thus, statistics is an indicator of how 'correct' your results are, if you have based the calculations on appropriate assumptions and interpreted the results correctly. Finally, statistics can be used in two ways: to describe a data set, or to draw inferences 
outside of the data set (descriptive and inferential statistics, respectively). The conditions for describing or drawing inferences are obviously not the same, and this means that it is important to define what is being studied, and how the conditions for a given test are met in the data set [5]. The notion of data type is crucial to all branches of statistics. Because all statistical tests make assumptions about types of data (they are quite picky). In corpus linguistics, we are almost always dealing with nominal data. [6] Language is a collection of statistical distributions: Weights for rules (phonetic, syntactic, etc) change when learning, a long time, between communities. The statistical work shows us the reality of language in specific stage or in two periods. Statistical methods are relevant to language acquisition, change, variation, generation and comprehension.

\section{WHAT IS THE COMPUTATIONAL APPROACH?}

The Computational Approach is the ability of a computer-system to be "Self-Aware" in some way. More specifically, we mean the property of a computational or formal system to be able to access and internalize some of its own properties.

\section{PROBLEMS OF STATISTICAL ANALYSIS IN LINGUISTIC STUDIES:}
A. Text Classification.
B. Morphological Statistical Classification.
C. Semantic Statistical Classification

\section{A. Text Classification.}

There is no doubt that statistical analysis is of crucial importance to verify the linguistic phenomenon. But could we make statistical analysis in the same manner to all of the TLG authors? For example, if we search the frequency of the

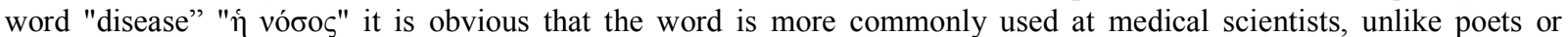
historians. So in the following statistics in TABLE 1, we'll limit the highest proportion of recurrence at three authors only:

TABLE 1

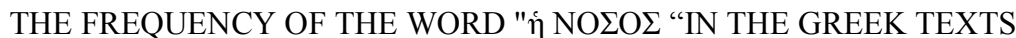

\begin{tabular}{|l|l|l|l|l|l|}
\hline Authors & Vocabulary & Frequency & Corpus & Percentage & Date \\
\hline Aretaeus & 60598 & 395 & $\begin{array}{l}\text { Corpus MedicorumGraecorum, De } \\
\text { causis et signis acutorum morborum }\end{array}$ & $0.65 \%$ & II b.c \\
\hline Hippocrates & 78666 & 286 & $\begin{array}{l}\text { Corpus Hippocraticum, De Diaeta In } \\
\text { Morbis Acutis }\end{array}$ & $0.36 \%$ & IV/V b.c \\
\hline Josephus & 305870 & 106 & Antiquitates Judaicae & $0.034 \%$ & I a.d \\
\hline
\end{tabular}

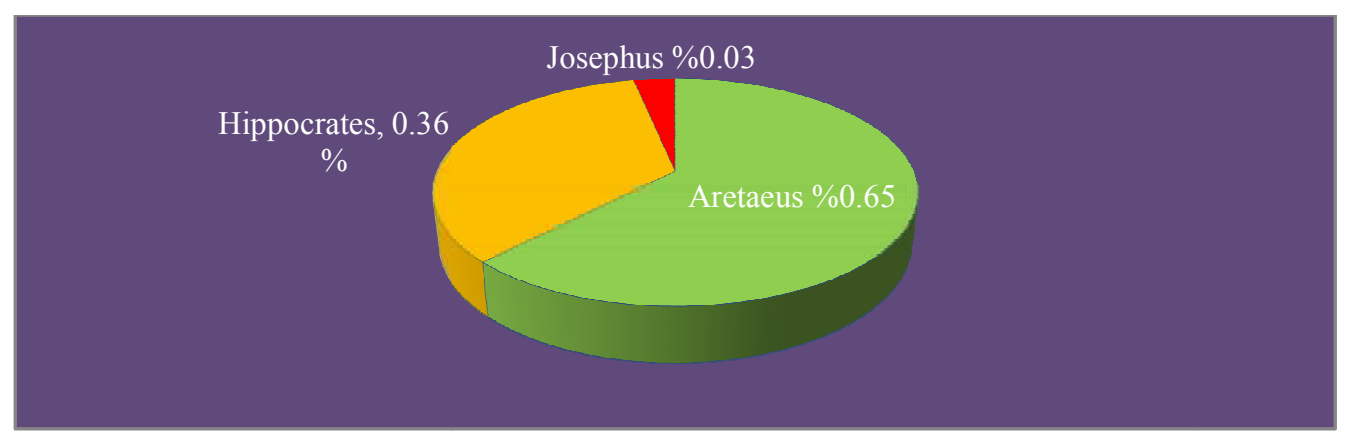

Figure 1: The frequency of the word " $\eta$ vó $\sigma o \varsigma$ " 
We conclude from the Figure 1 that Aretaeus is the most widely used of the word "í vóбos". So Josephus should be excluded from the comparison, as his writings were not about medicine, but the comparison between Aretaeus and Hippocrates is true. Anyway the comparison should be between two authors or more in the same topic.

So when we search again the frequency of the word "night" " $\mathfrak{\eta}$ v์ $\xi$ " at the two Greek Historians, Diodorus Siculus and Cassius Dio ( see TABLE 2).

TABLE 2

THE FREQUENCY OF THE WORD"í v̛́ $\xi^{\prime \prime}$ BETWEEN DIODORUS SICULUS AND CASSIUS DIO.

\begin{tabular}{|c|c|c|c|c|c|}
\hline Authors & vocabulary & frequency & Corpus & Percentage & Date \\
\hline Diodorus Siculus & 271501 & 255 & Bibliotheca Historica & $0.094 \%$ & I b.c \\
\hline Cassius Dio & 399409 & 165 & Historiae Romanae & $0.041 \%$ & II a.d \\
\hline
\end{tabular}

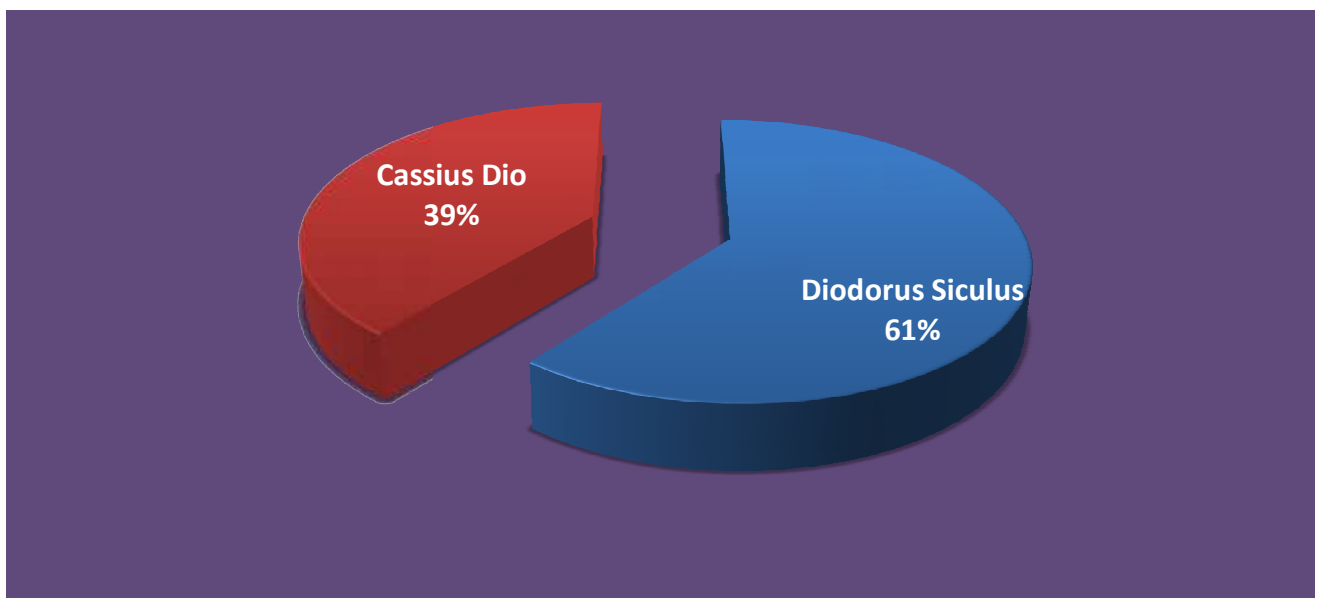

Figure 2: The frequency of the word " $\dot{\eta} v \mathfrak{\xi} \xi$

We conclude from the Figure 2 that the comparison between Diodorus Siculus and Cassius Dio is true. But we should organize the results historically from the past to the present, not form the most widely used.

\section{B. Morphological Statistical Classification.}

\section{- Multi-Function Morphemes:}

The morphological analysis of the texts is important in computational processing in general. The morphological statistical analysis should be done for vocabulary based on distinguishing nouns, adjectives, verbs, prepositions, particles ... etc., The researchers faced some morphological difficulties when counting morphemes, due to Multi-Function Morphemes. The Multi-Function Morphemes are big problems for the Arab students when studying ancient Greek language. Because the Greek Language has 15 multi-functional morphemes : $\{\varepsilon 1\},\{\theta \varepsilon v \tau \omega v\},\{\omega v\},\{\sigma \alpha 1\},\{\eta\},\{01\}$, $\{0 \varsigma\},\{0 v \sigma 1\},\{\varepsilon \tau \varepsilon\},\{\alpha\},\{o v\},\{o v v\},\{\varepsilon\},\{o v\},\{\sigma \theta o v\}$, and five of these morphemes are responsible for $60 \%$ Morphological Mistakes of Arab Students: $\{\varepsilon 1\},\{\theta \varepsilon v \tau \omega v\},\{\omega v\},\{\sigma \alpha 1\},\{\eta\} .[7]$

So the Multi-Function Morphemes pose also a problem for the current programs that search in TLG like Musaios (see Figure 3), TLG, Diogenes (see Figure 4), it's difficult to distinguish suffixes from nouns or verbs or particles ...etc, it searches only in word, without consideration if it is a noun or verb....etc, and gets the frequency without any linguistic classification. 


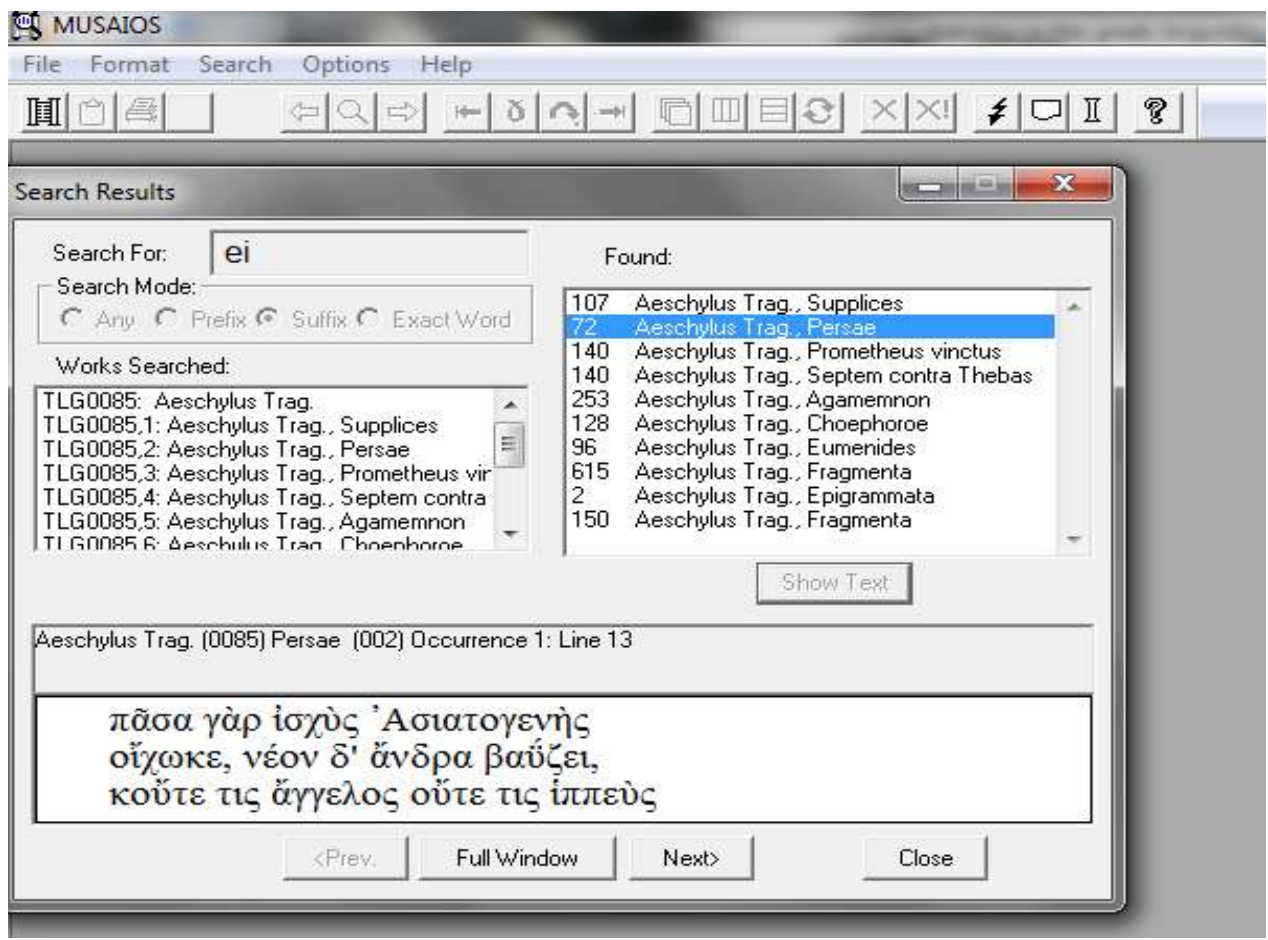

Figure 3: Searching the morpheme $\{\varepsilon \mathfrak{s}$ by Musaios

Diogenes

File Édit View Go Help

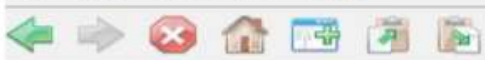

Apollonius Rhodius Epic., Argonautica

Book 1, line 6

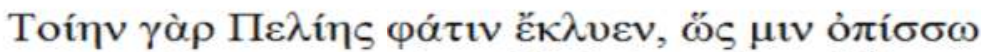

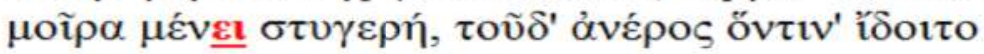

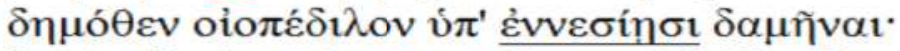

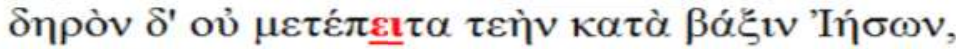

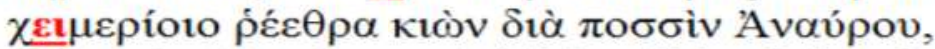

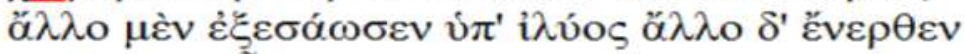

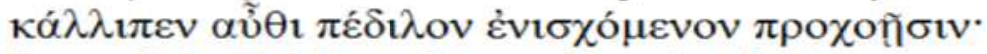

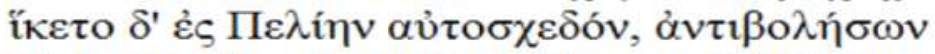

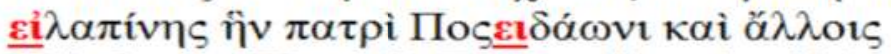

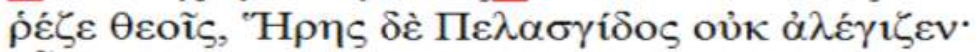

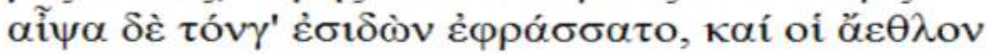

Figure 4: Searching the morpheme $\{\varepsilon ı\}$ by Diogenes 
For example the morpheme $\{\varepsilon 1\}$ is a multi-function morpheme used as:

- A suffix for Noun $3^{\text {rd }}$. Decl. Sing. Dat. Like $\pi$ ó $\lambda \varepsilon$.

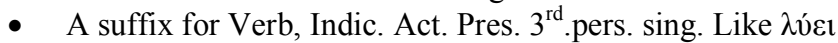

- A suffix for Verb, Indic. Act. Fut. $3^{\text {rd }}$.pers. sing. Like $\lambda u ́ \sigma \varepsilon ı$

- A suffix for Verb, Indic. Mid \&Pass. Pres. $2^{\text {nd }}$.pers. sing. Like $\lambda u ́ \varepsilon 1$

- A suffix for Verb, Indic. Mid. Fut. $2^{\text {nd }}$.pers. sing. Like $\lambda v ́ \sigma \varepsilon 1$.

- A suffix for Verb, Indic. Pass. Fut. $2^{\text {nd }}$.pers. sing. Like $\lambda v \theta \eta ́ \sigma \varepsilon 1$.

- A suffix for Verb, Indic. Act. Perf. $3^{\text {rd }}$ Pers. Sing. Like $\varepsilon \dot{\lambda} \varepsilon \lambda \hat{\kappa} \kappa \varepsilon 1$.

- Verb to be, Indic. Act. Pres. $2^{\text {nd }}$ Pers. Sing. Like $\varepsilon \tilde{i}$.

- The Adverb àcí ends with the diphthong eı which can't be distinguished by programs like Musaios.

- The conditional particle $\varepsilon i$ which was the same like the morpheme $\{\varepsilon 1\}$.

Practical Example:

The researcher performs a statistical analysis of the morpheme $\{\varepsilon l\}$ through the Persians of Aeschylus by using Musaios, and the results were as follows:

- The morpheme $\{\varepsilon 1\}$ was used 72 times in the Persians of Aeschylus (see Figure 5), without any morphological classification. So the researcher suggests to create a computer-system which includes a Data-Base of Greek vocabulary that can classify the Greek Texts by morphemes and be able to search and distinguish between texts.

- So the results can be classified as in TABLE 3:

And the computer system should summarize the results as follows:

- Verbs: 43 (see TABLE 3)

- Nouns: 12 (see TABLE 4)

- Adjectives: 2 (see TABLE 4)

- Particles And Adverbs: 12 (see TABLE 5)

\section{- Morpho-phonoligical Changes:}

Most inflection in Greek consists of adding an ending to a fixed stem. Greek shows great freedom in forming compound verbs by the addition of prepositional prefixes. From the stem $\gamma \rho \alpha \varphi$ - is derived $\pi \alpha \rho \alpha-\gamma \rho \alpha \varphi-\omega, \kappa \alpha \tau \alpha-\gamma \rho \alpha \varphi-$ $\omega$, $\delta \pi 0-\gamma \rho \alpha \varphi-\omega$, etc. It would be uneconomical to include $\pi \alpha \rho \alpha \gamma \rho \alpha \varphi-, \kappa \alpha \tau \alpha \gamma \rho \alpha \varphi-$, and $\delta \pi о \gamma \rho \alpha \varphi-$ in the dictionary since all are formed by the addition of common prefixes to the single verb stem $\gamma \rho \alpha \varphi-$. A difficulty arises, however, from the fact that the prefixes are often assimilated phonetically to the following letter. The prefix $\sigma v v$ - ' together' appears as $\sigma v v$ - before vowels and dental consonants, as $\sigma \nu \mu$ - before labial consonants, as $\sigma v \gamma$ - before guttural consonants, as $\sigma v \lambda$ - before $\lambda$, and as $\sigma \nu(\sigma)$ before $\sigma$. The prefix $\mu \varepsilon \tau \alpha$ - appears as $\mu \varepsilon \tau \alpha$ - before consonants, $\mu \varepsilon \theta$ - before vowels with aspiration and $\mu \varepsilon \tau$ - before vowels without aspiration. The program must recognize the assimilated forms of each prefix and must verify that the letter following the prefix could in fact have caused the suspected assimilation. In some cases a single verb is compounded with as many as three prefixes, each of which may appear in an assimilated form. The form $\sigma v \gamma \kappa \alpha \theta i \sigma \tau \eta \mu \mathrm{u}$ must be analyzed as o $\sigma v v+\kappa \alpha \tau \alpha+i ́ \sigma \tau \eta \mu \mathrm{l}, \sigma v v \varepsilon \pi \alpha v i ́ \sigma \eta \mu \mathrm{l}$ as $\sigma v v+\dot{\varepsilon} \pi \mathrm{l}+$ $\dot{\alpha} v \alpha+i \sigma \tau \eta$ t. Further complication is caused by the fact that verbal augments come before the stem but after the prefixes. The imperfect of $\sigma u \mu-\beta \alpha i v-\omega$ is $\sigma v v-\varepsilon \dot{\varepsilon}-\beta \alpha v-o v$. Thus, if the word cannot be analyzed directly into a stem and an ending, the program must attempt to remove prepositional prefixes from the beginning of the word. If a hypothetical prefix can be removed, the program proceeds to analyze the remainder of the word. If this analysis is successful the prefix is reunited with the word in the final analysis. In some cases the program makes more than one hypothetical division between prefix and stem. The verb $\alpha v \alpha \lambda v ́ \omega$ would generate three hypothetical divisions: $\alpha v \alpha-$

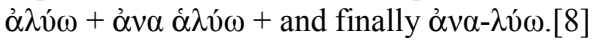


TABLE 3

VERBS IN PERSIANS OF AESCHYLUS

\begin{tabular}{|c|c|c|c|}
\hline Serial & Verb & Origin & Verse \\
\hline 1 & $\mathrm{~B} \alpha{ }^{\prime} \zeta \varepsilon 1$ & $\mathrm{~B} \alpha u ́ \zeta \omega$ & 13 \\
\hline 2 & $\Pi \varepsilon \dot{\varepsilon} \mu \pi \varepsilon \imath$ & $\Pi \varepsilon \dot{\varepsilon} \mu \pi \omega$ & 54 \\
\hline 3 & $\dot{\varepsilon} \lambda \alpha v ́ v \varepsilon 1$ & $\dot{\varepsilon} \lambda \alpha v^{\prime} \omega \omega$ & 75 \\
\hline 4 & $\dot{\varepsilon} \pi \alpha ́ \gamma \varepsilon 1$ & $\dot{\varepsilon} \pi \alpha ́ \gamma \omega$ & 85 \\
\hline 5 & П $\alpha \rho \alpha ́ \gamma \varepsilon 1$ & П $\alpha \rho \alpha ́ \gamma \omega$ & 111 \\
\hline 6 & 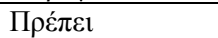 & 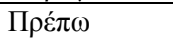 & 239,247 \\
\hline 7 & 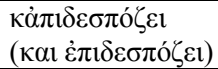 & $\dot{\varepsilon} \pi 1 \delta \varepsilon \sigma \pi \delta ́ \zeta \omega$ & 241 \\
\hline 8 & $\Phi \varepsilon ́ \rho \varepsilon 1$ & 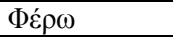 & 248 \\
\hline 9 & 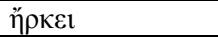 & 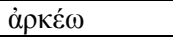 & 278 \\
\hline 10 & نं $\pi \varepsilon \rho \beta \alpha ́ \alpha \lambda \lambda \varepsilon \imath$ & نं $\pi \varepsilon \rho \beta \dot{\alpha} \lambda \lambda \omega$ & 291 \\
\hline 11 & $\mathrm{~B} \lambda \dot{\varepsilon} \pi \varepsilon 1$ & $\mathrm{~B} \lambda \dot{\varepsilon} \pi \omega$ & 299 \\
\hline 12 & $\varepsilon \not \chi \varepsilon 1$ & $\varepsilon \chi^{\prime} \chi \omega$ & $343,597,724$ \\
\hline 13 & $\Pi \lambda \eta \dot{\theta} \omega \omega$ & $\Pi \lambda \eta \dot{\eta} \theta \varepsilon \imath$ & 352 \\
\hline 14 & $\pi \rho о \varphi \omega v \varepsilon \tilde{\imath}$ & 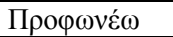 & 363 \\
\hline 15 & $\dot{\varepsilon} \pi \eta ̣ ́ \varepsilon 1$ & $\varepsilon ̌ \pi \varepsilon 1 \mu \iota$ & 378 \\
\hline 16 & $\dot{\varepsilon} \chi \omega ́ \rho \varepsilon \imath$ & $\mathrm{X} \omega \rho \varepsilon ́ \omega$ & 379 \\
\hline 17 & П $\alpha \rho \varepsilon \kappa \alpha ́ \lambda \varepsilon \iota$ & П $\alpha \rho \varepsilon \kappa \alpha ́ \lambda \omega$ & 380 \\
\hline 18 & $\kappa v \rho \varepsilon \tilde{i}$ & 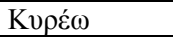 & 598 \\
\hline 19 & 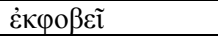 & 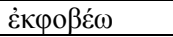 & 606 \\
\hline 20 & òíci & ơí & 633 \\
\hline 21 & $\mathrm{~K} \lambda u ́ \varepsilon 1$ & 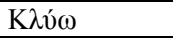 & 639 \\
\hline 22 & 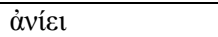 & o’vín & 649 \\
\hline 23 & 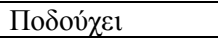 & 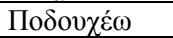 & 656 \\
\hline 24 & $\pi \mathrm{ov \varepsilon ĩ}$ & Пové $\omega$ & 682 \\
\hline 25 & 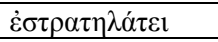 & $\sigma \tau \rho \alpha \tau \eta \lambda \alpha \tau \varepsilon \dot{\varepsilon} \omega$ & 717 \\
\hline 26 & $\sum \tau \varepsilon \dot{v} v \varepsilon \iota$ & $\sum \tau \varepsilon ́ v \omega$ & 730 \\
\hline 27 & $\varepsilon \check{\varepsilon} \rho \rho \varepsilon \imath$ & $\varepsilon ̌ \rho \rho \omega$ & 732 \\
\hline 28 & $\kappa \rho \alpha \tau \varepsilon \tilde{\imath}$ & K $\rho \alpha \tau \varepsilon \dot{\varepsilon} \omega$ & 738 \\
\hline 29 & 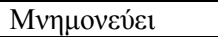 & 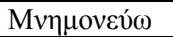 & 783 \\
\hline 30 & 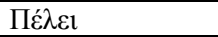 & $\Pi \varepsilon \dot{\lambda} \lambda \omega$ & 792 \\
\hline 31 & $\sigma v \mu \mu \alpha \chi \varepsilon \tilde{\imath}$ & $\Sigma v \mu \mu \alpha \chi \varepsilon \dot{\varepsilon} \omega$ & 793 \\
\hline 32 & 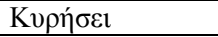 & 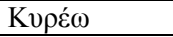 & 797 \\
\hline 33 & $\Sigma v \mu \beta \alpha$ íveı & $\Sigma v \mu \beta \alpha i ́ v \omega$ & 802 \\
\hline 34 & $\Lambda \varepsilon i ́ \pi \varepsilon \iota$ & $\Lambda \operatorname{cí}^{\prime} \pi \omega$ & 804 \\
\hline 35 & 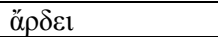 & 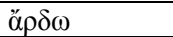 & 806 \\
\hline 36 & 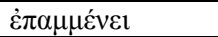 & 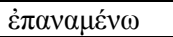 & 807 \\
\hline 37 & $\omega \dot{\varphi} \varphi \varepsilon \lambda \varepsilon \tilde{i}$ & $\dot{\omega} \varphi \varepsilon \lambda \varepsilon \dot{\varepsilon} \omega$ & 842 \\
\hline 38 & $\Delta \alpha ́ \kappa v \varepsilon \imath$ & $\Delta \alpha ́ \kappa v \omega$ & 846 \\
\hline 39 & $\dot{\alpha} \mu \pi \dot{\varepsilon} \chi \varepsilon \imath$ & $\dot{\alpha} \mu \pi \dot{\varepsilon} \chi \omega$ & 848 \\
\hline 40 & $\alpha i \alpha \alpha_{\zeta} \varepsilon 1$ & $\alpha i \alpha ́ \zeta \omega$ & 922 \\
\hline 41 & $\bar{\alpha} v \tau \varepsilon \tilde{i}$ & $\dot{\alpha} v \tau \varepsilon \dot{\varepsilon} \omega$ & 1058 \\
\hline
\end{tabular}

TABLE 4

NOUNS \&ADJECTIVES

\begin{tabular}{|c|c|c|c|}
\hline Serial & Noun & Origin & Verse \\
\hline 1. & $\dot{\alpha} \lambda \hat{v} \xi \varepsilon 1$ & $\alpha \not \alpha \nu v \xi 1 \varsigma$ & 108 \\
\hline 2. & $\pi \circ \lambda \varepsilon \hat{\imath}$ & Пó $\lambda 1 \zeta$ & $307,715,781$ \\
\hline 3. & 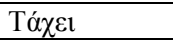 & Táxos & 342 \\
\hline 4. & $\pi \varepsilon v \theta \varepsilon \tilde{\imath}$ & 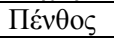 & 579 \\
\hline 5. & $\sum \tau \dot{\varepsilon} v \varepsilon \iota$ & $\sum \tau \varepsilon \dot{v} \nu{ }^{\prime}$ & 683 \\
\hline 6. & Tóp$\beta \varepsilon \imath$ & Tópßos & 696 \\
\hline 7. & 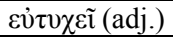 & 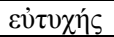 & 709 \\
\hline 8. & $\Delta \alpha \rho \varepsilon \tilde{\imath}$ & $\Delta \alpha \rho \varepsilon \tilde{i} о \zeta$ & 713 \\
\hline 9. & $\beta \rho \alpha \chi \varepsilon \tilde{i}$ (adj.) & $B \rho \alpha \chi v ́ \varsigma$ & 713 \\
\hline 10. & 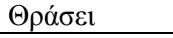 & 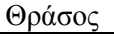 & 744 \\
\hline 11. & $\varphi \rho o v \varepsilon \tilde{i}$ & Фpóvis & 782 \\
\hline 12. & 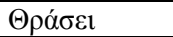 & 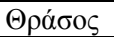 & 831 \\
\hline
\end{tabular}


TABLE 5

PARTICLES \& ADVERBS

\begin{tabular}{|c|c|c|}
\hline Serial & Adv./Particles & Verse \\
\hline 1 & кعì & 295 \\
\hline 2 & $\dot{\varepsilon} \kappa \varepsilon \tilde{\imath}$ & 319 \\
\hline 3 & $\varepsilon \hat{i}$ & $357,369,631,790,791,800$ \\
\hline 4 & $\dot{\varepsilon} \pi \varepsilon i ́$ & $377,656,697,703$ \\
\hline
\end{tabular}

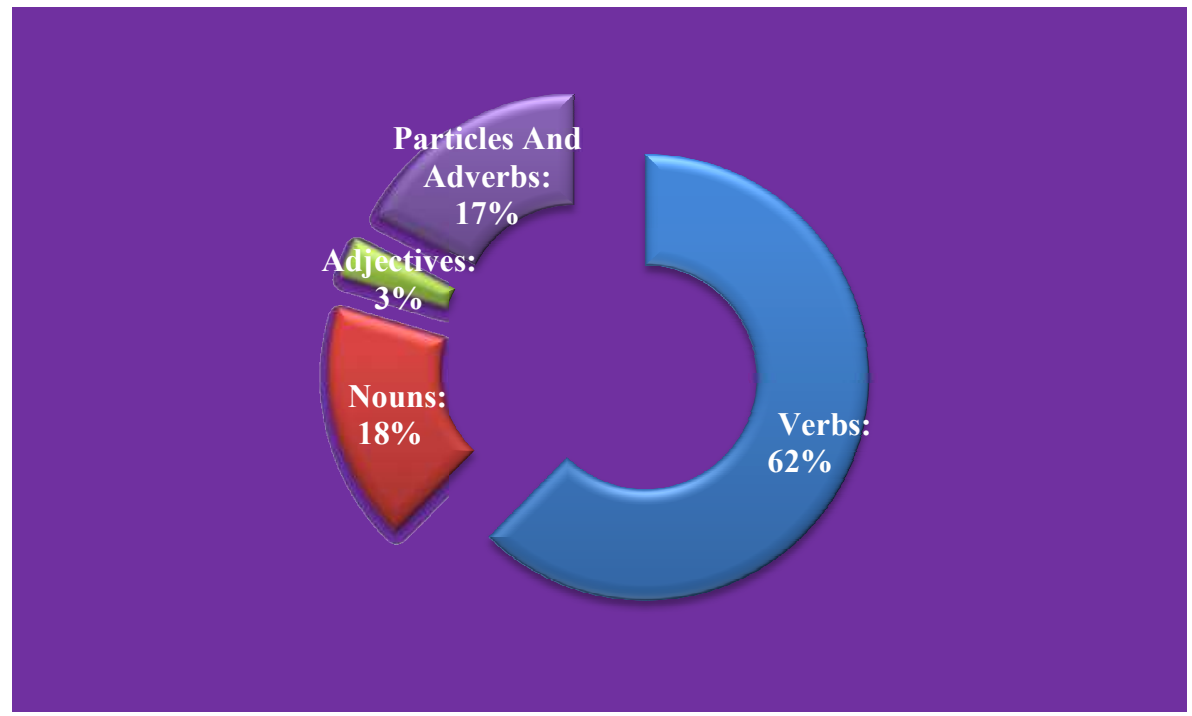

Figure 5: The Morpheme $\{\varepsilon 1\}$ in the Persians of Aeschylus

\section{Statistical Semantic Classification for Greek Texts}

What is the content of the text? Or to be more precise: What are the basic elements that should be identified in order to understand the basic meaning of the text? Whether poetry or prose. Every text contains some basic phrases that constitute the framework: So the problem is to identify the central core of the text that carries meaning basics. This is the first critical step, before any attempt at explanation can be provided. If there is no program capable to perform semantic analysis of Greek texts, how it can be automated semantic classification of Greek texts? Can it make a comparison of Greek texts to determine the influence among poets and writers? The current computer programs can't distinguish semantic fields of Greek texts. But we can't measure some semantic features for Greek writers as activity and optimism and certainty, realism and commonality.

The Researcher proposes to create a computer system for the analysis and statistical classification of Greek texts - The system should identify most Greek words automatically.

- Computer System should contain different combinations of Greek lexicons, and supports a database of Greek vocabulary which shows the stages of semantic development of the Greek vocabulary through the ages and in different contexts.

- The system should support different files with extensions such as: (.txt, doc., .docx., .html, .xml, .... Etc)

- The system should give the users multiple options for counting and classification of linguistic data.

- The system should allow users to compare the results among authors.

- The system should also allow users to choose dictionaries, which can be compared through texts, to give further semantic analysis

- The system should also display the results in statistical tables and charts.

\section{CONCLUSION}

The Researcher finds through the study that:

- Greek texts can be processed automatically in the light of digital content, which, now, is online.

- Using computer in counting different language phenomena, but there are some problems in morphological processing due to the presence of multiple morphemes function as mentioned above. 
- No one can deny the benefits of statistics in general linguistic studies, but there are regulations to be followed when studying the any linguistic phenomenon including the following:

a) Selection of the type of text (literary / poetic / scientific / .... etc).

b) The selection of the author (poet / historian / doctor / ...... etc).

c) Choose period (the same period / two periods/ etc ...).

d) Choose the means of research and comparison.

e) Comparing texts in different semantic contexts.

\section{REFERENCES}

[1] http://www.perseus.tufts.edu/hopper/collection?collection=Perseus:collection:Greco-Roman

[2] N-gram is A mechanism analyzes to determine the frequency of the word Uni gram, or phrase Bi gram \& Tri gram or collocations in the corpus, with the presentation of the results sorted by number of iterations, and said ratio to the number of words of the corpus. http://nlpwp.org/book/chap-ngrams.xhtml (accessed 15 November 2014).

[3] L. Padrò, Statistical Methods for Natural Language Processing, Columbia University, 2009, p. 7.

[4] N. Chomsky, Of Minds and Language, Biolinguistics 1, 2007, p.10. http://www.biolinguistics.eu (accessed 3 November 2014).

[5] M. Davidian \& T. A., Louis, What Is Statistics?, American Statistical Association, http://www.amstat.org/careers/whatisstatistics.cfm (accessed 14 November 2014)

[6] G. B. Jenset, Basic Statistics for Corpus Linguistics, Handout for methods seminar in English linguistics. Fall 2008. https://www.researchgate.net/publication/265965333_Basic_statistics_for_corpus_linguistics (accessed 1 August 2014).

[7]A. Farrag, (2003) Redesign the Curriculum for Bilingual Greek and Latin for Arab Student, Critical and applied Study, according to the Theory of Error Analysis in the Light of Educational Linguistics, Egyptian Society of Comparative Literature, Brochures-Comparisons, Brochure (1), 2003, pp.86-94. (in Arabic)

[8] D. W. Packard, Computer-assisted Morphological Analysis of Ancient Greek, Computational And Mathematical Linguistics: Proceedings of the International Conference on Computational Linguistics, Pisa 21/8 to 1/9/ 1973, Vol. 2, | pp.345-346, http://ww.aclweb.org/anthology/C73-2026 (accessed 2 December 2014).

\section{Dr. Abdel-Monem Ahmed Zaki}

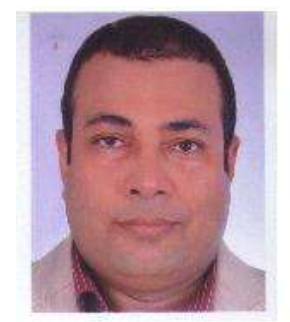

Director of the Computer Unit, Faculty of Arts, Ain Shams University.

He is Lecturer of computational linguistics in the Department of Ancient European Civilization, Faculty of Arts, Ain Shams University. He obtained his MA in Historical Linguistics in 2007, and his PhD in Computational Processing of Ancient Greek Lexicons in 2012. His main areas of interest are concerned with corpus work, morphological and lexical analysis.

Dr. Abdel-Monem Has many scientific works in Natural Language Processing published in international conferences and periodicals, and a member in many scientific organizations: (1) Egyptian Society of Language Engineering, Cairo, (2) American Philological Association - USA, (3) Egyptian Society of Greek and Roman Studies, Cairo (4) The Association of Egyptian Papyrologists, Cairo.

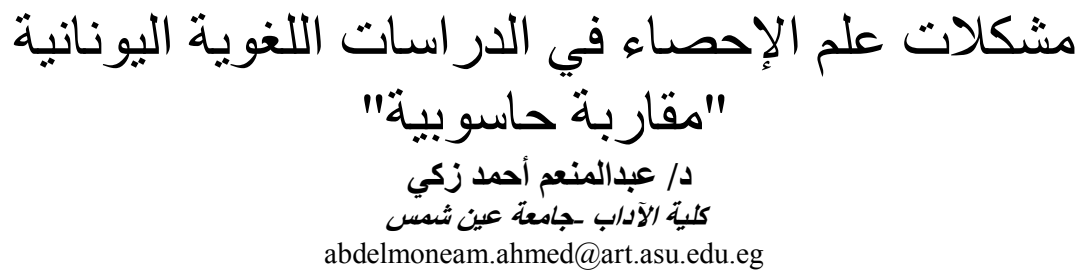

بحاول الباحث من خلال هذه الدراسة إلقاء الضوء على أهمية علم الإحصاء في الدراسات اللغوية، ويجيب عن بعض الاستفسار ات مثل: ما هي مشكلات علم الإحصاء في الدراسات اللغوية؟ وما هي الإستر اتيجية المتبعة لدر اسة ظاهرة لغويةٌ وما هي البيانات التي يمكن معالجتها؟ وكيف بمكن صباغة الفرضيات و النتائج؟ كما 
يضع الباحث الأسس لإنشاء نظام حاسوبي يشتمل على قاعدة بيانات للمفردات اليونانية وذلك لإعانة الباحثين في

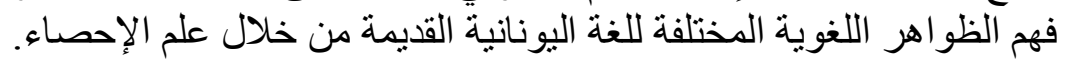

